\title{
Notes and Comment
}

\section{Do rats and pigeons readily acquire instrumental responses for food in the presence of free food?}

\author{
ROBERT L. WELKER \\ and \\ MEREDITH A. WEIDENMAN \\ Mount Holyoke College \\ South Hadley, Massachusetts 01075
}

Osborne (1977) provided a long-needed review and analysis of investigations of instrumental responding for food reward in the presence of freely available food. This is an important step in our understanding of the variables involved in the "contrafreeloading" phenomenon, but we believe that an important issue was obscured in the review. The issue involves the distinction between acquisition and maintenance of responding in the presence of freely available food.

Regarding conditions of maintenance, it has been well established that rats and pigeons will continue to respond for food in the presence of free food after they have been trained to respond in the absence of free food (e.g., Carder \& Berkowitz, 1970; Carlson \& Riccio, 1976; Jensen, 1963; Knutson \& Carlson, 1973; Neuringer, 1970; Osborne \& Shelby, 1975; Singh, 1970; Tarte, Townsend, Vernon, \& Rovner, 1974). In many of these studies, response-produced food constituted more than $90 \%$ of the subjects' total food intake during sessions in which both response-produced and free food were available.

It is not well established, however, that naive rats and pigeons "readily acquire" instrumental responses for food in the presence of freely available food as reported by Osborne (1977, pp. 223 and 229). There are only a few published articles which report such findings, each using small numbers of subjects, and some presenting less than conclusive results.

Kopp, Bourland, Tarte, and Vernon (1976) housed two female Holtzman rats in Grason-Stadler twolever chambers and two female Wistar rats in BRS/LVE single-lever chambers for 98-100 days. In each chamber, pellets could be procured by leverpressing according to a continuous schedule of reinforcement (CRF) or from a dish filled with $600-1,000$ pellets. Cumulative numbers of leverpresses plotted over successive blocks of 10 days showed approximate linear functions for the two Wistar rats, and discontinuous increases in the frequency of leverpressing by the two Holtzman rats only after protracted exposure to the chambers, on the 30th and 48 th days of housing. The mean numbers of leverpresses per day (8-53) were small given the $24-\mathrm{h}$ periods in which they could occur, and the mean per- centages of total pellets consumed that were procured by the lever were small $(2.1 \%-13.5 \%)$ relative to studies of the maintenance of leverpressing in which much shorter session durations were used, typically about $60 \mathrm{~min}$.

The only published report that we have found that convincingly demonstrates that rats will readily acquire leverpressing for food in the presence of freely available food is that of Coburn and Tart (1976). Four Wistar rats were raised in impoverished environments and four in enriched environments for 39 days. They were then housed in chambers in which food pellets could be procured by pressing a lever (CRF) or from a metal dish that was replenished with 600 pellets daily. Subjects were placed in the chambers at 60 days of age and remained there for 25-30 days. All four animals raised in impoverished conditions procured substantial amounts of food via the lever (the subjects averaged 162-297 pellets per day), and response-produced food represented substantial portions of their total daily intake (43\%-79\%). In contrast, leverpressing occurred very infrequently for subjects raised in enriched conditions. Coburn and Tarte elaborated upon the extremely high activity levels of subjects reared in impoverished environments, and therefore acquisition of leverpressing by these subjects may be attributed to elevated operant levels of leverpressing.

The only published data that we are aware of which reports acquisition of responding for food by pigeons in the presence of free food is that of Neuringer (1969). Two pigeons were housed in separate operant chambers for 33 consecutive days. One learned to procure grain from a hopper by pecking a continuously illuminated response key and the other by manipulating the armature of a microswitch protruding from the floor of the chamber. Both responses were acquired within 4 days of exposure to the chamber, and as many as 300 responses occurred per $24-\mathrm{h}$ period. Relative amounts of food consumed from the hopper vs. the free source were not reported, but covering the hopper entrance with a transparent shield produced a marked reduction in the frequency of both responses.

In view of the paucity of published data, we conclude that it is premature to state that rats and pigeons will "readily acquire" instrumental responses for food in the presence of free food. Two pigeons raised in standard laboratory environments required about 4 days to do so, and two rats from standard rearing conditions required at least 30 days to achieve low levels of responding. Only following exposure to impoverished environments have 
four rats been unambiguously shown to readily acquire leverpressing in the presence of free food, and this may be a function of elevated operant levels.

We feel that it is important to distinguish between conditions of acquisition and maintenance of responding for food in the presence of freely available food until a greater amount of research has been conducted with conditions of acquisition. The results of this research will carry important implications for our understanding of why responding occurs in the presence of free food. Failure to note the distinctions between acquisition and maintenance at this stage of development may misdirect research and theoretical treatments of the "contrafreeloading" phenomenon.

\section{REFERENCES}

Carder, B., \& Berkowitz, K. Rats' preference for earned in comparison with free food. Science, 1970, 167, 1273-1274.

Carlson, C. W., \& Riccio, D. C. Experience with the reinforcer and the preference for earned rather than free reinforcers in rats. Animal Learning \& Behavior, 1976, 4, 269-272.

COBURN, J. F., \& TARTE, R. D. The effect of rearing environments on the contrafreeloading phenomenon in rats. Journal of the Experimental Analysis of Behavior, 1976, 26, 289-294.
Jensen, G. D. Preference for bar pressing over "freeloading" as a function of number of rewarded presses. Journal of Experimental Psychology, 1963, 65, 451-454.

Knutson, J. F., \& Carlson, C. W. Operant responding with free access to the reinforcer: A replication and extension. Animal Learning \& Behavior, 1973, 1, 133-136.

Kopp, J., Bourland, G., Tarte, R. D., \& Vernon, C. R. Acquisition of bar pressing in nondeprived rats. Psychological Record. 1976, 26, 49-54.

Neuringer, A. J. Animals respond for food in the presence of free food. Science, 1969, 166, 399-401.

Neuringer, A. J. Many responses per food reward with free food present. Science, 1970, 169, 503-504.

OsBorne, S. R. The free food (contrafreeloading) phenomenon: A review and analysis. Animal Learning \& Behavior, 1977, 5, 221-235.

Osborne, S. R., \& Shelby, M. Stimulus change as a factor in response maintenance with free food available. Journal of the Experimental Analysis of Behavior, 1975, 24, 17-21.

SingH, D. Preference for bar pressing to obtain reward over freeloading in rats and children. Journal of Comparative and Physiological Psychology, 1970, 73, 320-327.

TARTe, R. D., Townsend, S. G., Vernon, C. R., \& Rovner, L. An examination of various deprivation-reward combinations in the barpressing vs. freeloading phenomenon in rats. Bulletin of the Psychonomic Society, 1974, 3. 227-229.

(Received for publication December 9, 1977; accepted July 7,1978 .) 